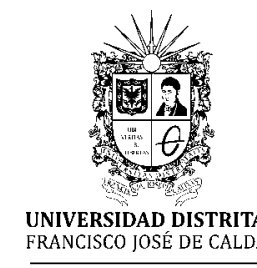

\title{
Ana $Z$ y la literatura de fantasía en la infancia: un acto de descubrimiento
}

\author{
Ana Z and Fantasy Literature in Childhood: An Act of Discovery \\ Laura Paola Fajardo Leal ${ }^{1}$
}

Para citar este artículo: Fajardo, L. P. (2017). Ana Z y la

literatura de fantasía en la infancia. Un acto de descubrimiento. Infancias Imágenes, 16(2), 326-329.

\section{Resumen}

La presente reflexión se centra en el escenario de lo fantástico que caracteriza a la literatura infantil y que claramente se presenta en el libro titulado Ana $Z$, ¿dónde vas?, de la escritora ítalo-brasileña Marina Colasanti. Es la lectura literaria un acto de desocultamiento de los misterios de la vida a los cuales los niños y niñas se ven en la necesidad de explorar. Así, el texto en mención responde fundamentalmente al siguiente interrogante: ¿de qué manera la obra Ana Z, ¿dónde vas? de Marina Colasanti permite descubrir otros mundos que trascienden la cotidianidad y las vivencias de la infancia?

Palabras clave: lectura; niñez; imaginación.

\begin{abstract}
The present reflection focuses on the scenery of the fantastic character of children's literature and that is clearly presented in the book entitled Ana Z, ¿dónde vas? by the Italian-Brazilian writer Marina Colasanti. Literature is an act of uncovering the mysteries of life to which children find themselves in need of exploration. Thus, this text responds fundamentally to the following question: In what way Ana Z, ¿dónde vas? by Marina Colasanti allows to discover other worlds that transcend the everyday and the experiences of childhood?
\end{abstract}

Keywords: reading; childhood; imagination.

\footnotetext{
1 Licenciada en Educación Básica con énfasis en Humanidades y Lengua Castellana, Universidad Distrital Francisco José de Caldas. Correo electrónico: arualeal1800@gmail.com
} 
Una de las características de la literatura fantástica es justamente su frontal rechazo a la razón, su libertad con respecto a lo real... La literatura fantástica recorre otros caminos más profundos, más oscuros, caminos que la razón no frecuenta y donde la lógica se pierde. (Colasanti, 2004, p. 93)

Durante el proceso de aprendizaje escolar, y fundamentalmente en la primera infancia, la lectura se asume como una experiencia de encuentro con la construcción del lenguaje, pero, sobre todo, con el diálogo entre dos actores: el lector y el texto (escrito o gráfico). De allí que el primer acercamiento al acto de leer, el cual se mantiene a lo largo de la vida, se encuentre asociado con el descifrar el contenido de lo literario y mundos simbólicos, lo que aviva el deseo del niño por despertar las bestias que duermen profundamente, explorar tierras desconocidas o simplemente adentrarse en la conquista de un espacio habitado por la fantasía.

A razón de lo anterior, el propósito de esta reflexión consiste en develar cómo la literatura de fantasía, ejemplificada con la obra Ana Z, ¿dónde vas? de Marina Colasanti, actúa como escenario para avivar la sed de descubrimiento del niño (quien se construye como lector a medida que establece un encuentro enriquecedor con los textos que conoce durante su etapa inicial dentro y fuera de la escuela).

Marina Colasanti, con nacionalidad ítalo-brasileña, es escritora, traductora y periodista. Su obra ha recorrido diversidad de los géneros, representada en más de 40 libros publicados. Su inmersión en el campo de la literatura infantil y juvenil deviene de sus momentos como periodista y editora. Ana $Z$, ¿dónde vas?, libro publicado en 1993, ganó en 1994 el premio Jabuti a la mejor obra brasileña de ficción.

Ana $Z$, ¿dónde vas? es un claro ejemplo de una mirada alternativa a lo fantástico en la cual despertar la bravura de los monstruos, rescatar princesas y vivir en castillos de cristal no son los únicos sucesos trascendentales. La fantasía, en esencia, le permite al niño jugar con la realidad y la ficción y crear universos extraordinarios, de modo que esta obra cambia dicho convencionalismo.
En los confines de esta historia habita una niña llamada Ana, quien, sin pensarlo, un día decide acercarse a un pozo que encuentra unos metros más allá de su casa. Observa el pozo y se acerca a él intentando descubrir qué hay en su profundidad. Sin advertirlo, las perlas de su collar se enredan y caen a la oscuridad del pozo obligando a Ana a descender por una escalerilla hasta llegar a una superficie firme y comenzar a buscar las perlas de su collar.

Si bien durante la historia Ana no se encuentra con los típicos monstruos o las anheladas princesas que necesitan ser salvadas de las Ilamas, de las garras del malvado o de los hechizos de las brujas, sí toma de la mano al lector y lo guía durante toda su travesía que va más allá de hacer el intento por encontrar sus perlas y rearmar su collar. Tanto Ana como el lector caminan juntos sobre peligrosos pantanos, áridos senderos, empedradas calzadas y húmedas tierras. El viaje termina siendo compartido, pues las acciones de Ana repercuten significativamente en el modo de lectura del niño, o quizá del adulto. Colasanti manifiesta en esta historia que lo fantástico no se reduce a un solo público lector, sino que, por el contrario, es un universo lleno de posibilidades y acercamientos. Al inicio de la historia Ana y el inquieto lector emprenden su viaje guiados por una vocecilla escondida la cual es aparentemente quien da vida a Ana y a todas sus aventuras:

Vamos a descender con Ana. Despacio. Pasamos una pierna por encima del brocal, tanteando la grada con el pie, el cuerpo todavía con la mitad afuera y la mitad adentro. Ahora la otra pierna. Cuidado. El brocal del pozo es resbaloso, las paredes Ilenas de lodo. Ana no sabe si sus manos están sudando, o si es la humedad de las gradas, pero se agarra fuerte. Los pies tantean. El corazón está mucho más apresurado que ella. Una grada. Otra. Una más. (Colasanti, 1993, p. 12)

Este viaje compartido es una de las estrategias clave que utiliza Colasanti para adentrar al lector al mundo del descubrimiento, pues este último no actúa exclusivamente como tal, sino que se encuentra vinculado a todos los sucesos que hilan la historia. De allí que: 
Inmerso en batallas ficticias que propicia la lectura, el niño actúa de varios modos al mismo tiempo. Al principio es un observador; luego se convierte, gracias a la identificación con los personajes, en un participante, y al completar, automática e instintivamente, el escenario que el autor ofrece poniendo rostro a los personajes, se convierte también en coautor. (Colasanti, 2004, p. 57)

En Ana $Z$, ¿dónde vas? las batallas ficticias no son precisamente los combates de ejércitos de fantasía, sino que se representan a partir de toda la cadena de sucesos y exploraciones con diversas culturas que se tejen alrededor de la vida de Ana cuando ingresa al pozo. Desde la desaparición de los peces que al parecer se han Ilevado sus perlas, pasando por el encuentro con el sarcófago egipcio hasta llegar al Medio Oriente, Ana mantiene su sed por descubrir y ello la invita constantemente a preguntarlo todo, incluso en los instantes menos apropiados; a Ana no le interesa si desconoce a las personas porque son sus nuevos compañeros de travesía que la guían a lo largo de ella. Sin embargo, no por eso deja de inquietarse: "Ana está tan llena de preguntas que el pecho parece que le rasca. Pero ya que no puede preguntar todo lo que quiere saber, pregunta al menos lo más importante" (Colasanti, 1993, p. 29).

Después de tanto preguntar, Ana llega al universo de las dunas a través de una puerta muy pequeña pero la sorpresa del lector es mil veces más grande:

El mentón de Ana no se cae, porque está bien sujeto al rostro y, sobre todo, porque Ana ni siquiera abre la boca. Como siempre se ve muy sorprendida, hace exactamente lo contrario. Cierra bien apretados los labios, para que no se le salga la sorpresa. (Colasanti, 1993, p. 46)

¡El desierto! Ana siente emoción y miedo instantáneamente y piensa: "El miedo visto por fuera no se parece ni siquiera al que la gente siente por dentro" (Colasanti, 1993, p. 47). Aun así, decide enfrentar sus temores y se encuentra con una cultura distinta que la lleva a develar todos sus secretos.

En el capítulo VII, Ana se topa con una gran acacia y quiere recostarse sobre su tronco, pero
"¡Cataplum! en vez del apoyo del tronco, Ana encuentra el vacío y cae de espaldas golpeándose la cabeza en el suelo... extiende su mano sin encontrar nada, intenta agarrar una hoja, pero solo agarra el aire" (Colasanti, 1993, p. 57). Luego entiende, gracias a una mujer que la encuentra y sabe de su existencia, que "las cosas no son pero la gente hace que las cosas sean" (Colasanti, 1993, p. 59).

Esto último pone de manifiesto que Ana hace la figura del lector niño cotidiano que no solo se encuentra súbitamente con lo desconocido sino que aprende de él más que lo que desea saber al preguntar y el deseo insaciable por desenmascarar el mundo la hace cambiar. Ana se convierte en Sherezade al encontrarse con un sultán que la retiene en su reino para escuchar las aventuras que solo ella podría narrar. En este punto de la historia, la narración cobra una gran importancia pues se despiertan los sucesos de las fábulas y los cuentos populares de los hermanos Grimm.

Ana sabe que, como Sherezade, será llevada con el verdugo si su compilado de narraciones se acaba en cualquier instante. Así que, como en las grandes anécdotas de fantasía, Ana duerme y el viento la conduce a otra nueva historia. En el Medio Oriente, Ana retoma su camino con el lector, que ha visto lo mismo que ella, quien se une a una caravana de personas que también le guía. Ana, como cualquier niño, jamás quiere estar sola y más en un lugar que no conoce. Finalmente, y después de todos los obstáculos que Ana debe sobrepasar para encontrar la salida, halla un tren que la conduce a casa y de vuelta retoma todo aquello que conoció inicialmente. Desconoce el tiempo, en la fantasía el tiempo cronológico no existe.

Ana $Z$, ¿dónde vas? es una obra que reinventa los imaginarios del niño adentrándolo en un universo de posibilidades que trascienden lo real. Ana y el lector realizan un viaje no solo alrededor de la diversidad cultural sino en torno a la vida. Al respecto, Colasanti afirma que:

La literatura traspasa cualquier edad, forma y contenido. Es un contenido denso, una sólida reflexión sobre la vida y nuestro estar en el mundo. Un contenido que nos lleva a reflexionar. Es una forma que, siendo muy cuidada, no revela el trabajo intenso que 
la genera, pero, por el contrario, resulta llena de frescura. La forma puede ser, en sí, un viaje. (2004)

Ana y el lector finalizan la historia con un destino preciso que parte de la construcción de la experiencia, dicha no hubiese podido existir sin la fantasía y la sed de Ana por indagar y cuestionarse todo lo que la rodea. En últimas, de allí parte el descubrir en el niño, del acto de interrogarse desde las cosas más pequeñas hasta aquello que resulta inverosímil para él.

En última instancia, la literatura no es otra cosa que un largo e interminable discurso sobre la vida, un artificio donde mediante la narrativa, los seres humanos elaboran sus pasiones, sus angustias, sus miedos y se acercan al gran enigma del ser. Leyendo no solo aprendemos a poner en palabras nuestros propios pensamientos. También obedeciendo a representaciones simbólicas, aprendemos de la vida. (Colasanti, 2004)

\section{Referencias}

Colasanti, M. (1993). Ana Z, ¿dónde vas? Medellín: Susaeta.

. (2004). Fragata para tierras lejanas, conferencias sobre literatura. Bogotá: Grupo Editorial Norma. 